\title{
The Shortage-Surplus Paradox: A Literature Review of Primary Health Care Accessibility
}

\author{
Melissa M Terry, Daniel R Terry*, Ha Hoang, Chona Hannah \\ University Department of Rural Health, University of Tasmania, Locked Bag 1372, Launceston, Tasmania 7250, Australia \\ *Corresponding Author: Daniel.Terry@utas.edu.au
}

Copyright (C) 2013 Horizon Research Publishing All rights reserved.

\begin{abstract}
The National Primary Health Care Strategy in Australia recommends primary health care services need to be clinically and culturally appropriate and delivered in a timely and affordable manner. However simultaneously recognised, access is still inequitable in among various population groups and many areas of Australia. Geographical Information System (GIS) have been used to explore geographical health disparities, planning health care service delivery and provide data in a meaningful way to inform public health strategies. Moreover, GIS has also been used to spatially analyse, measure and provide insight into a population's accessibility to health care services. A literature search was conducted to identify studies which examined primary health care accessibility using GIS techniques among various urban and rural populations. A limited number of studies demonstrated in addition to distance; time; and location, low socioeconomic status, Culturally and Linguistically Diverse (CALD) background among other factors influences health care access. In addition, other factors were identified to impact health care access, which is an individualised process, influenced by individual characteristics, beliefs, attitudes, and an individual's activity space. As health care accessibility becomes more prominent within policy, among practitioners and increasingly researched, it has the potential to move beyond recognising areas of poor accessibility among individuals and communities. With a greater integration of both spatial and aspatial data, the process has the likelihood, to provide greater insight into patient behaviour, public perception, amelioration service quality and improve population health and wellbeing.
\end{abstract}

Keywords Health Care Access, Rural, Spatial Accessibility, Primary Health Care, GIS

\section{Introduction}

The Department of Health and Ageing [1], stated in the National Primary Health Care Strategy that all "Australians should have access to primary health care services which keep people well and manage ill-health". As such, it was recommended that primary health care services needed to be clinically and culturally appropriate and delivered in a timely and affordable manner. However, it was recognised that with an average of 5.1 GP services per capita, access was still inequitable in many areas of Australia and among various population groups. [1] This was made obvious in a recent article, where a super clinic in South Australia was being built where other services already existed, while five kilometres away a community with high socio-economic disadvantage had lost their last GP. Accessing this new clinic was problematic as many in the community did not drive and were aiming to walk or use public transport to access the new super clinic. [2]

Health care has many definitions and meanings as it is more than the absence of disease. [3] To some, health care and health oriented services is hospital or medical care, while to others it may mean a plethora of other 'health' oriented services, from primary health care right through non-medical services or complementary and alternative medical care. [4] Nevertheless, as primary health care services is the first-point-of-contact which occurs between the community and the national health system in Australia, this will be used to define access to health care within this literature review. [4-6]

Similar to defining health care, access to health care is complex and may mean many things to different people. It is "not limited to the availability of care, the ability to get to and pay for available care, or the act of seeking and utilising available care". [7] Potential or realised access is influenced by many other social and geographical aspects. [5,8-10] Thus by its own nature, access has many complex and challenging meanings with no clear consensus in terms of definition, meaning or how it can be measured. $[4,11]$ Penchansky and Thomas [12], state “'Access' is defined here as a concept representing the degree of 'fit' between the clients and the system".

The framework they outline highlights five interdependent dimensions to determine and aid individuals to understand what access may mean. These dimensions include availability, accessibility, accommodation, affordability, and acceptability. [12] Khan and Bhardwaj 
[13], further delineate these dimensions into geographic and socio-organisational or spatial and aspatial subcategories. Where "availability and accessibility are spatial in nature, while the remaining three dimensions are related to social, financing and cultural aspects".[5]

Beyond defining access, it must be noted a health disparity exists between rural and urban populations as "rural and remote people experience poorer health as evidenced by higher mortality, lower life expectancy and an increase in incidence of some diseases". [14] A number of factors impact the health and wellbeing of individuals in rural and remote areas. This includes larger distances to primary health care services, workforce shortages and the characteristics of rural and remote populations, which impact health care utilisation. [15]

\section{Geographical Information System and Health Access}

Despite the various factors which impact health care utilisation, geographic access of health services continues to impact on the delay in treatment, increased hospitalisations, but also the overall health and wellbeing of individuals. $[10,16]$ Geographical Information System (GIS), as a technology, is relatively new for health care research and it has been used to understand geographic health disparities which exist. GIS has been stated to be difficult to define, but is a system designed to gather, store and manipulate geographical data, which can be analysed and present for a various number of applications. [17] This includes, but is not limited to environmental science, education, hydrology, crime, defence, agriculture, geology, urban planning and the social sciences. [17,18]

In addition, GIS has been used to explore geographical health disparities, planning health care service delivery and planning health care management strategies. $[5,19]$ It can be a means to provide data in a meaningful way to inform public health strategies and how best to meet the health needs of a local or whole population. Moreover, GIS has also been used to spatially analyse, examine and measure the accessibility of health care services. [10] As such, to understand the use of spatial analysis in health care, a number of methods currently used in health GIS will be examined.

\section{Measuring Health Access}

In health care, access does not have an established method of measurement; as such there are a number of methods used to calculate spatial accessibility which are area-based or distance-based. [5,20-22] The distance-based methods include Manhattan, Euclidean, road network distance and travel time. [22] Each method has both positives and negatives to their several abilities to measure spatial accessibility. For example, Manhattan measures a distance between two points as if followed at right angles, which has a propensity to overestimate distance. [5,9] Conversely, Euclidean measures distance between the same two points 'as the crow flies' which would be the most direct route, which can underestimate distance, however is less complex to calculate. [5,19] In addition, travel time can be useful, however does not take into account travel conditions, nevertheless road network distance has been argued to provide the most accurate measure of distance. [5]

Beyond calculating distance, area-based methods measure accessibility through provider-to-patient or supply-demand ratio. These can be simply used to identify where needs exist by using a simple ratio of physicians to the population to measure geographical access. $[11,19,22]$ For example, the World Health Organisations initial provider-to-patient guidelines were 1 physician per 1000 population. [3,23] However, the current guidelines state accessibility to Primary Health Care should be at an optimal ratio of 3.5 physicians per 1,000 head of population. [24] This then can be used to comprehend where deficiencies are within and among countries. The provider-to-patient ratio is a more popular method to measure accessibility and does not required a GIS tool for its calculation. Although, provider-to-patient ratios are good for overall understanding of supply and demand of services, it does not account for borders which individuals can cross nor does it take into account distance or time. [16]

\subsection{Alternative Methods of Measuring Access}

As there is a plethora of methods used measure health accessibility and much literature discussing these methods and their development, this literature review will concentrate on the most recent, such as the floating catchment method, the two-step floating catchment area and other advances which are used to measure health accessibility.

\subsubsection{Floating Catchment Areas (FCA)}

The floating catchment area which is at times is referred to the floating catchment method is akin with the Kernel density estimation model. [11,25,26] It was initially developed to assess job accessibility $[27,28]$ but later used to determine health care access. [20,29] Rather than using fixed state, municipal or census borders - a predetermined 'drive time' radius around a centre point or centroid is used as the 'catchment' area. This catchment area is determined by the maximum distance or travel time which individuals are willing to undertake to access health care. This can differ depending on individuals or populations under investigation. [20,29,30]

As a catchment area or 'window' floats over an area, particularly a population area or a centroid of census tract, "the density of events within the window is used to represent the density at the centre [sic] of the window". [29] For example, provider-to-patient ratios are calculated for those health care providers which fall within the FCA over 
a population or centroid of a census tract. [20,29,31] Nevertheless, the assumptions used with FCAs are that all individuals have equal access to health care providers and the FCA model is focused only on supply. [29,30]

\subsubsection{The Two-step Floating Catchment Area (2SFCA)}

To overcome the limitations of the FCA, an alternate model was first envisioned by Radke and $\mathrm{Mu}$ [32] who undertook the development of spatial decomposition method of the FCA. This was then further developed and modified by Luo and Wang [29] to become the two-step floating catchment area (2SFCA), where accessibility and availability of services are assessed simultaneously and intuitively. [25,31,33] It was stated the strength and limitation of the 2SFCA is its flexibility. It can be used among the rural and urban populations, but certain rules that apply in one context need to change as they may not work in another. [7]

The 2SFCA method uses provider-to-patient ratios while focusing on the demand for each medical site by assessing the service catchment, where all populations that fall within the drive threshold from each service. This then is calculated to give a provider-to-patient ratio according to capacity and demand. The second step focusses on the population catchment, where all services nearby and fall within the drive threshold from each population is calculated to give a provider-to-patient ratio, which is added to the ratio from step one. $[30,33]$ If these two catchment areas overlap, it is anticipated the service accessibility available to those individuals is much greater, however if they do not overlap this indicates less accessibility. [29,34] Lu and Wang [29] state "the method considers interaction between patients and physicians across administrative borders based on travel times, and computes an accessibility measure that varies from one tract to another."

\subsubsection{The E2SFCA and 3SFCA}

The initial 2SFCA was further developed to become the 'enhanced two-step floating catchment area' (E2SFCA). This was achieved by implementing, distance decay function, where separate travel time zones were incorporated for each of the physician and population floating catchment areas. [35] This allowed greater accuracy in determining health care access, as distance decay shows as distance between two locations increases, their interaction deteriorates. [36] Additional enhancements have been conducted in terms of using a variable catchment size and a step versus continuous decay models, as the same distance-decay function does not apply to all scenarios. $[7,37]$ The E2SFCA was further developed to become the three-step floating catchment area (3SFCA), which was to minimize the health care-demand overestimation which was argued to occur in previous models. [6] In addition the recommended catchment size of 30 minutes' drive was extended in this model to 60 minutes. [33]

\subsubsection{Index of Rural Access}

To address a number of the limitations within the 2SFCA model, McGrail \& Humphreys [30,38], developed the Index of Rural Access. The IRA was to address a number of the aspatial barriers encountered by rural populations when accessing primary health care, such as service availability, health needs and mobility. [30,38] Within this index, there are four stages to undertake, which ranges from measuring spatial accessibility using an improved 2SFCA; measuring health needs using Disability Adjusted Life Years (DALYs); measuring mobility; and then incorporating health needs and mobility within the 2SFCA method.

\section{Objectives}

The purpose of this paper was to conduct a literature review of recent research to identify studies which examined primary health care accessibility using GIS techniques among both urban and rural populations. This was to isolate and determine other than distance, time and location, what other factors influences health care access such as patient behaviour, public perception and service quality. The principle aim was to identify areas in the research which require further research and investigation.

\section{Methods}

\subsection{Literature Search Strategies}

An online literature search was conducted in January 2012, where a primary online search of MEDLINE, Cumulative Index to Nursing and Allied Health (CINAHL), PubMed, PsycInfo, GeoBase, INSPEC and IEEE ASPP databases was searched from 1993 - 2013. This was to identify journal articles which discussed and highlighted health care access and spatial accessibility among any population. Keyword searches were used and included word combinations and synonyms of health care access; spatial accessibility; spatial analysis; health care mapping; primary health care; GIS; geometric modeling; gravity modeling; floating catchment area; two-step floating catchment area; 2SFCA and E2SFCA.

The aim was to identify spatial accessibility mapping outcomes for individuals and communities, including similar or adjunct articles. A secondary manual search was conducted within the reference list of the initial identified articles. This was undertaken to separate any additional studies which were not captured within the online databases. In addition, a subsequent online search was conducted by searching Google Scholar and Summon Search through the University of Tasmania's library for generic literature related the subject area. This type of search was worthy as an additional search method as it highlighted literature which was closely related the key words and terms used. Each of these methods yielded a large number of articles and reports. 


\subsection{Inclusion Criteria}

The inclusion criteria for the current literature review included articles which were in English. The research also needed to measure the spatial accessibility of individuals to a primary health care facility or provider, such as a family physician or general practitioner. Although the researchers are primarily focused on rural health care accessibility in Australia, the criteria remained inclusive of international research conducted in both rural and urban (including dense urban) areas. This was due to the literature review focusing on identifying and examining studies which highlighted primary health care accessibility using GIS techniques. Lastly, the inclusion criteria for each of the articles were they needed to report on the spatial and aspatial factors, such as socioeconomic disadvantages, sociocultural barriers, and high health care needs were also included.

\section{Results}

The literature search captured 98 articles and reports which were screened and selected for their content regarding spatial accessibility of primary health care. In most cases primary health care was interpreted to be a primary health physician, rather than primary health care itself which is outline by WHO. [3] Each article was further reviewed with 57 articles and reports excluded as they were organisational reports [39] or articles which did not contain relevant research highlighting populations measures of accessibility primary health care. 18 articles identified pertained to spatial accessibility; health outcomes; literature reviews; or were articles which reported spatial accessibility tool development, comparison and evaluation, as shown in Figure 1.

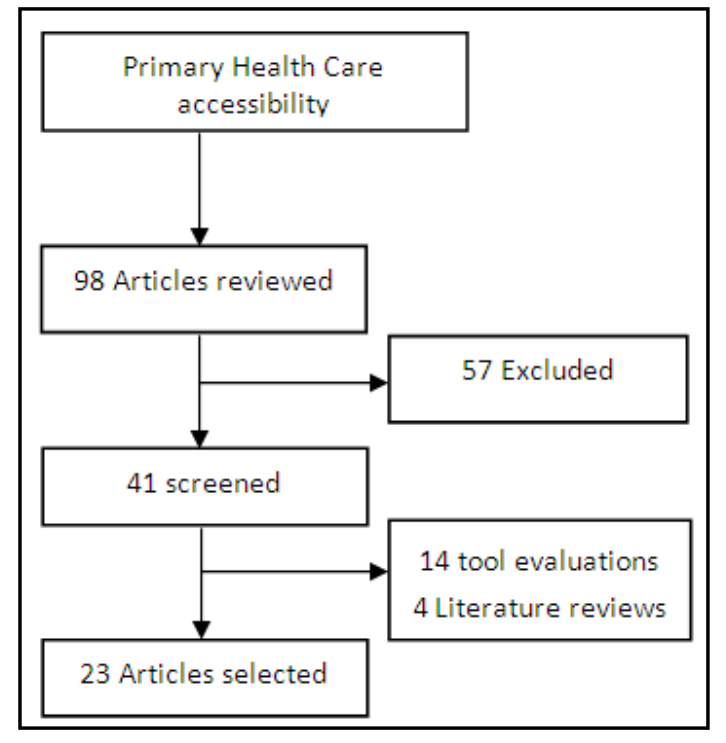

Figure 1. Literature search results

Within the remaining 23 articles, there was a large variation among the research on how spatial accessibility was measured. Despite this variation, it was noted eight studies had used the either a 2SFCA or 3SFCA to measure spatial accessibility, seven used either time or Euclidean distance from place of residence or census area to provider, one had used FCA, while another had used a Modified version of gravity model and the remaining six studied used various number of GIS methods to understand the spatial accessibility of the population. Overall, six of the 23 studies were informed by empirical data to provide, further insight into spatial accessibility, as outlined below and in Table 1 . These articles were subsequently reviewed and further separated into the populations which they were measuring, rural, urban, whole populations and specific populations 
Table 1. Research examining spatial accessibility of primary health care

\begin{tabular}{|c|c|c|c|c|}
\hline Author & Location & Population (sample size) & Spatial accessibility measure(s) & Study Results \\
\hline $\begin{array}{l}\text { (Guagliardo et al., } \\
\text { 2004) }\end{array}$ & $\begin{array}{l}\text { Washington D.C, } \\
\text { USA }\end{array}$ & Urban paediatric population & $\begin{array}{l}\text { Spatial accessibility to primary care services of } \\
\text { paediatric primary care providers to child } \\
\text { population's residence. }\end{array}$ & $\begin{array}{c}\text { Spatial access to primary care is not equitably distributed within } \\
\text { cities and that this variation results in poorer access in areas of } \\
\text { general lower amenity and for racial and socioeconomic } \\
\text { disadvantaged population groups }\end{array}$ \\
\hline $\begin{array}{l}\text { (Hawthorne and } \\
\text { Kwan, 2012) }\end{array}$ & $\begin{array}{l}\text { Columbus, Ohio, } \\
\text { USA }\end{array}$ & Low income urban populations & $\begin{array}{l}\text { GIS - street distance measures from clinic to place } \\
\text { of residence and satisfaction-adjusted distance } \\
\text { (SAD). Individual in-depth interview data to } \\
\text { construct new GIS accessibility measures }\end{array}$ & $\begin{array}{l}\text { Satisfaction adjusted distance (SAD) measure accounts for the } \\
\text { perceived distance some residents feel as they search for high-quality } \\
\text { health care in lower-income urban areas. }\end{array}$ \\
\hline (Luo et al., 2004) & Illinois, USA & Urban and rural populations & $\begin{array}{l}\text { Two-step floating catchment area (2SFCA) model } \\
\text { and socioeconomic and demographic variables were } \\
\text { included. Principle component analyse and factor } \\
\text { analysis }\end{array}$ & $\begin{array}{l}\text { Spatial accessibility was concentrated in rural areas with limited } \\
\text { pockets in urban areas. The poorest accessibility was associated with } \\
\text { populations with high scores of socioeconomically disadvantages, } \\
\text { sociocultural barriers, and high health care needs. }\end{array}$ \\
\hline $\begin{array}{l}\text { (McLafferty et al., } \\
\text { 2011) }\end{array}$ & Illinois, USA & $\begin{array}{l}\text { Urban and rural populations } \\
\text { (Total and African-Americans) }\end{array}$ & $\begin{array}{l}\text { Two-step floating catchment area (2SFCA) using } \\
\text { STATA }\end{array}$ & $\begin{array}{c}\text { Spatial access to primary care physicians showed rural - urban } \\
\text { inequalities in risk of late stage breast cancer are associated with } \\
\text { differences in the demographic characteristics of area populations and } \\
\text { differences in the social and spatial characteristics. }\end{array}$ \\
\hline $\begin{array}{l}\text { (Pathman et al., } \\
\text { 2006) }\end{array}$ & $\begin{array}{c}\text { Rural } \\
\text { Southeast, USA }\end{array}$ & Rural population & $\begin{array}{l}\text { Telephone survey concerning access concepts and } \\
\text { dimensions incorporating the principal components } \\
\text { of the prevailing models of access, access issues and } \\
\text { the perception regarding travel for care (STATA 8.2) }\end{array}$ & $\begin{array}{l}\text { More individuals reported traveling over } 30 \text { minutes for outpatient } \\
\text { care and more reported travel difficulties in low physician areas; } \\
\text { however density of primary care physicians was unrelated to reported } \\
\text { barriers to care, satisfaction of care and people's use of services. }\end{array}$ \\
\hline (Teach et al., 2006) & $\begin{array}{l}\text { Washington D.C } \\
\text { and Maryland, } \\
\text { USA }\end{array}$ & $\begin{array}{l}\text { Urban, disadvantaged and } \\
\text { minority population of children } \\
\text { up to } 17 \text { years with asthma }\end{array}$ & $\begin{array}{l}\text { Secondary analysis of data from RCT of children } \\
\text { seeking acute asthma care in the emergency } \\
\text { department. }\end{array}$ & $\begin{array}{l}\text { Patients with higher spatial accessibility to primary care services } \\
\text { made significantly more scheduled visits for asthma care. }\end{array}$ \\
\hline (Bell et al., 2013) & $\begin{array}{l}\text { Mississauga, } \\
\text { Ontario, Canada }\end{array}$ & Urban population & $\begin{array}{l}\text { 3SFCA model and aspatial factors of potential } \\
\text { access challenges to primary health care were } \\
\text { included in the analysis }\end{array}$ & $\begin{array}{l}\text { Access significantly differs between neighbourhoods for all spatial } \\
\text { and aspatial dimensions of access. Accessibility is considerably } \\
\text { reduced for linguistic minorities and for those who might not have a } \\
\text { dedicated family physician. }\end{array}$ \\
\hline $\begin{array}{l}\text { (Bissonnette et al., } \\
\text { 2012) }\end{array}$ & $\begin{array}{l}\text { Mississauga, } \\
\text { Ontario, Canada }\end{array}$ & Urban population & $\begin{array}{l}\text { Modified two-step floating catchment area (2SFCA) } \\
\text { model and aspatial factors of potential access } \\
\text { challenges to primary health care }\end{array}$ & $\begin{array}{l}\text { Accessibility to primary care is dependent on both spatial and aspatia } \\
\text { dimensions of access and accessibility is reduced for linguistic } \\
\text { minorities and new migrants. }\end{array}$ \\
\hline
\end{tabular}

(Ngui and Apparicio, 2011)
Montreal, Canada $\quad$ Urban and rural populations
Comparison of a two-step floating catchment area (2SFCA) and a E2SFCA
Spatial access to primary care is not equitably distributed and this variation results in poorer access in areas of general lower amenity and for disadvantaged population groups. Differences observed between both tools.

\section{(Wanga and} Roisman, 2011)
Toronto, Canada

Mainland Chinese immigrants
Gravity model; two-step floating catchment area (2SFCA) model. Physician-seeking behaviours collected through two rounds of questionnaires
Spatial mismatch in the supply of and demand for culturally sensitive care, and residential location

Is the primary factor that determines spatial accessibility to family physicians? 


\begin{tabular}{|c|c|c|c|c|}
\hline $\begin{array}{l}\text { (Hyndman and } \\
\text { Holman, 2001) }\end{array}$ & Perth, Australia & Urban population & $\begin{array}{c}\text { Comparison of distance to surgeries with the } \\
\text { distance to nearest local surgeries. Survey to gather } \\
\text { operational data. }\end{array}$ & $\begin{array}{c}\text { Across urban Perth there was a relatively equitable and generally } \\
\text { appropriate provision of general practice services }\end{array}$ \\
\hline (Lê et al., 2010) & $\begin{array}{l}\text { Meander Valley, } \\
\text { Tasmania, } \\
\text { Australia }\end{array}$ & Urban and rural populations & $\begin{array}{l}\text { GIS - Datasets used. A self-reported health survey } \\
\text { and semi-structured interviews. Socioeconomic, } \\
\text { demographic, health disparity, access to health } \\
\text { services data and the perceptions regarding } \\
\text { accessibility. }\end{array}$ & $\begin{array}{l}\text { The socio-economic disadvantage in region reflected the health } \\
\text { disparities and poorer health conditions and the affordability to seek } \\
\text { care. This was compounded by the lower levels of available health } \\
\text { services and private health insurance. }\end{array}$ \\
\hline $\begin{array}{l}\text { (Roeger et al., } \\
\text { 2010) }\end{array}$ & $\begin{array}{l}\text { Adelaide, } \\
\text { Australia }\end{array}$ & Urban population & $\begin{array}{l}\text { Two-step floating catchment area (2SFCA) model } \\
\text { with 8km radius. Assessing the distance from the } \\
\text { central business district (CBD) and socioeconomic } \\
\text { status (SES). }\end{array}$ & $\begin{array}{l}\text { Residents of urban Adelaide have low GP access with an inequitable } \\
\text { spatial distribution of GPs within urban Adelaide. Residents in the } \\
\text { outer suburbs and those with lower social economic status most } \\
\text { disadvantaged. }\end{array}$ \\
\hline (Scott et al., 2006) & $\begin{array}{l}\text { Western } \\
\text { Australia, } \\
\text { Australia }\end{array}$ & Rural population & $\begin{array}{l}\text { Floating catchment area method (FCA) with } 100 \mathrm{~km} \\
\text { radius }\end{array}$ & $\begin{array}{l}\text { Small-area estimates detected greater variation } \\
\text { in access than depicted by conventional methods }\end{array}$ \\
\hline $\begin{array}{l}\text { (Astell-Burt et al., } \\
\text { 2011) }\end{array}$ & $\begin{array}{l}\text { Tayside, } \\
\text { Scotland, UK }\end{array}$ & $\begin{array}{l}\text { Urban and rural populations } \\
\text { with } \\
\text { Hepatitis } \mathrm{C}(\mathrm{HCV})\end{array}$ & $\begin{array}{l}\text { Measured using the travel-time between centre of } \\
\text { census area and the nearest primary health care } \\
\text { facility }\end{array}$ & $\begin{array}{c}\text { As travel time increased significant reduction in detections rates of } \\
\mathrm{HCV} \text { occurred. Thus poor geographic access to primary associated } \\
\text { with lower detection rates. }\end{array}$ \\
\hline $\begin{array}{l}\text { (Comber et al., } \\
\text { 2011) }\end{array}$ & $\begin{array}{l}\text { Leicestershire, } \\
\text { UK }\end{array}$ & Urban and rural populations & $\begin{array}{l}\text { Geographically Weighted Regression (GWR). } \\
\text { Attitudes survey. }\end{array}$ & $\begin{array}{c}\text { Accessing different health facilities is significantly related to health } \\
\text { status and car ownership, whilst the impact of geographic distance } \\
\text { depends on the service. }\end{array}$ \\
\hline $\begin{array}{c}\text { (Parker and } \\
\text { Campbell, 1998) }\end{array}$ & $\begin{array}{l}\text { West Lothian, } \\
\text { Scotland, UK }\end{array}$ & Urban and rural populations & $\begin{array}{l}\text { GIS of clinic post code and distance from residential } \\
\text { post codes. A patient questionnaire administered at } \\
18 \text { general medical practices for demographic data. }\end{array}$ & $\begin{array}{l}\text { Spatial access to primary care is not equitably distributed and this } \\
\text { variation results in poorer access in areas of general lower amenity } \\
\text { and for disadvantaged population groups. Distance decay observed. }\end{array}$ \\
\hline $\begin{array}{l}\text { (Bagheri et al., } \\
\text { 2006) }\end{array}$ & $\begin{array}{l}\text { Rural Otago, } \\
\text { New Zealand }\end{array}$ & Rural population & $\begin{array}{l}\text { Two-step floating catchment area (2SFCA) model, } \\
\text { network analysis tools and socio-demographic data }\end{array}$ & $\begin{array}{l}\text { Spatial access to primary care not equitably distributed. Variation } \\
\text { results in poorer access in areas of general lower amenity and } \\
\text { disadvantaged population groups }\end{array}$ \\
\hline
\end{tabular}




\begin{tabular}{|c|c|c|c|c|}
\hline $\begin{array}{l}\text { (Brabyn and } \\
\text { Barnett, 2004) }\end{array}$ & New Zealand & Whole population & $\begin{array}{l}\text { GIS - calculating population/GP ratios and least cost } \\
\text { path analysis (LCPA) and Network analysis. }\end{array}$ & $\begin{array}{l}\text { Regional variations in geographical accessibility in New Zealand. } \\
\text { Differences are dependent upon calculation method. Variation results } \\
\text { in poorer access in areas of general lower amenity and for } \\
\text { disadvantaged population. }\end{array}$ \\
\hline $\begin{array}{l}\text { (Monnet et al., } \\
\text { 2008) }\end{array}$ & France & Urban and rural populations & Distance to nearest provider & $\begin{array}{l}\text { Detection rates of Hepatitis } \mathrm{C} \text { decreased as the distance to general } \\
\text { practitioner increased which occurred more in urban areas. }\end{array}$ \\
\hline $\begin{array}{l}\text { (Gillespie et al., } \\
\quad \text { 2012) }\end{array}$ & Ireland & Urban and rural populations & $\begin{array}{l}\text { Investigating health care centre accessibility on type } \\
\text { II diabetes screening. GIS }\end{array}$ & $\begin{array}{l}\text { As travel time increased from PHC there was a reduction in } \\
\text { detections rates of diabetes. Poor geographic access to primary is } \\
\text { associated with lower rates of detection. }\end{array}$ \\
\hline $\begin{array}{l}\text { (Peciūra et al., } \\
\text { 2006) }\end{array}$ & $\begin{array}{l}\text { Klaipèda, } \\
\text { Taurage, and } \\
\text { Vilnius } \\
\text { municipalities, } \\
\text { Lithuania }\end{array}$ & Whole population & $\begin{array}{l}\text { Geometric modeling and applied graphics with a } \\
3 \mathrm{~km} \text { radius from primary health care services to } \\
\text { account for walkability }\end{array}$ & $\begin{array}{l}\text { Study was evaluated geometric modeling and the use of digital } \\
\text { graphics to inform future investment planning. It showed some areas } \\
\text { in the three municipalities which were inadequate for those who did } \\
\text { not drive and relied on the limited public transport services in the } \\
\text { areas. }\end{array}$ \\
\hline (Wong et al., 2012) & Singapore & Urban population & $\begin{array}{c}\text { GIS of clinic visits and distance from residential } \\
\text { post codes (ArcGIS v9.1) }\end{array}$ & $\begin{array}{l}\text { Jurong West and Sembawang areas of Singapore were ranked as top } \\
\text { areas with poor spatial accessibility to polyclinic services. }\end{array}$ \\
\hline
\end{tabular}




\subsection{Spatial Accessibility in Rural Areas}

Among the three studies which focused on rural populations, each had specific aims, objectives and results. For example, the study conducted by Bagheri, et al. [23] was specifically concentrated on developing a new approach for measuring spatial accessibility by mapping the accessibility with primary health of rural communities in Otago, New Zealand. In addition, Scott, et al. [40] were concerned with determining the percentage of rural populations which had accessibility with a GP within a $100 \mathrm{~km}$ radius in rural Western Australia. Conversely, the third study, did not specifically use GIS to measure spatial accessibility to primary health care providers, but undertook a qualitative approach to understand how to improve access to health care services. [41]

\subsection{Spatial Accessibility in Urban Areas}

In addition to the rural studies, there were five principle studies which focussed specifically on spatial access within urban areas. One single study was conducted in Singapore; however its main aim was to investigate where the best possible place was to build new polyclinics. Its objective was to ensure minimum travel was to be incurred, while maximising patient outcomes. [5] Among the other urban studies, many had commensurate findings, which pertained to reduced accessibility among those with low socioeconomic status, CALD groups or those who are living in outer or most disadvantaged urban areas. $[6,21,31,42,43]$

It was shown in metropolitan Adelaide, Australia; there was an inequitable distribution of GPs within $16 \%$ of the urban population living in areas which was considered areas of GP workforce shortage. [44] However, in metropolitan Perth, Australia, it was shown those who were living in areas of greater disadvantage, were those who has less access to a female GP, unable to access after-hours GP or see their own GP at short notice. Nevertheless, in Washington D.C., it was shown those asthmatic children, who had poor spatial accessibility to their paediatric primary care provider, were those who had lower socioeconomic status or were those children from CALD backgrounds. This was in spite of Washington D.C. being a highly urbanised with high paediatric primary care providers per child population. [45]

\subsection{Spatial Accessibility across Total Populations}

The majority of studies identified within the literature review had examined the spatial accessibility of health across both urban and rural areas. For example, a study was conducted and examined spatial accessibility across the whole of New Zealand. It was found that $3.4 \%$ of the population were more than 30 minutes from a GP, which occurred among those with higher socioeconomic status. [46] Despite this, a number of concerns about the study were highlighted, in that the study examined and reported the population-to-provider ratio rather than the provider-to-population ratio. Nevertheless, the study provides a picture of the spatial accessibility of health across the country.

Among other studies, it was shown that access to health care was deemed 'reasonable', however actual or perceived poor health care access occurred, particularly among those individuals who had low socioeconomic status; did not own a car; did not own their own home; were from CALD backgrounds; had higher health care needs; or had long term illness. [45,47,48] Nevertheless, in one study many patients did not attend a primary health care provider which was geographically closest to their home. [48]

This may be due to many factors, which centre on the importance of place rather than distance to primary health care, where utilisation of primary health care occurs within one's 'activity space'. [49] Activity space is stated to be the locations where individuals visit in their normal daily activities. [50,51] This may include personal shopping, banking, attending place of employment, visiting friends and family. [51,52]

\subsection{Spatial Accessibility within Specific Populations}

Beyond the examination of rural and urban access issues, it was noted there were a very small number of studies which specifically researched spatial accessibility of health care on specific populations. In addition, many of the other studies provided some insight into specific populations within the broader research conducted. As such, two studies examined specific populations in France and Scotland, which investigated access to primary health care providers and the screening rates of Hepatitis C (HCV). [53,54] It showed those with lower socioeconomic status had greater access to primary health care providers, however lower detection rates of $\mathrm{HCV}$ was in proportion to travel time to a GP. Similarly, in Ireland, screening for gestational diabetes mellitus was shown to be influenced by distance to screening sites. [44]

Among the other studies, access to language-specific primary care services was examined in a Canadian city which showed that CALD populations have poorer access language appropriate care. [6] In addition, it was shown those who are Maori, in New Zealand also have poorer access to health care where travel time to a primary health care service one of the highest contributors. [46] Similarly, the study conducted by Wanga \& Roisman [55] examined Physician-seeking behaviours of Mainland Chinese immigrants in Toronto, Canada. They showed place of residence was the principle factor which determined health care access. Conversely, when compared to the overall population, it was shown African Americans have poor access to primary care providers for late-stage breast cancer diagnosis in rural areas, while the remaining population have poor access in urban areas. [45] 


\section{Discussion}

Within the literature there were limited studies that provided insight into the spatial accessibility which individuals, communities and populations have to primary health care. This may be due to spatial accessibility being in its early stages of being sufficiently well-defined and developed as an emerging field in GIS research. [23] Many of the 23 studies examined have similar findings, in terms of distance or time impacted on individual's ability to access health care. Nevertheless, it was shown that there were many more factors involved with spatial accessibility than distance, time and location which influence health care choice. The other more prominent factors, which occurred in both rural and urban areas that impact spatial accessibility, include low socioeconomic status, living in a disadvantaged area and CALD background. In addition, car ownership, home ownership, having a long term illness or high health care needs; and after-hours access were also identified in several studies.

Despite providing increased accuracy to health care access and identifying health professional shortage areas, most studies which have used the 2SFCA, E2SFCA or other GIS analysis methods have not be substantiated by "empirical data on 'real' health service access behaviour and its relationship to geography". [7] It has been suggested there are other factors which impact health care access and provider choice. In addition, it is a complex individualised process which is influenced by individual characteristics, beliefs, attitudes, and activity space which need to be further explored. [6,15,38]

Currently, only six studies examined the aspatial factors, which impact on accessibility through the use of survey questionnaires [48,55], surveys [41,47,56], in-depth or semi-structured interviews $[56,57]$. The empirical data provided greater insight and depth to a number of studies, by contributing to a conceptual and theoretical understanding of the attitudes, perceptions and experiences of healthcare accessibility. [47,48,57] However, in some cases the results cannot be largely generalised due to the small number of study participants. [57] This lack of empirical data has meant other studies have used, "a number of assumptions or estimations were necessary regarding... population behaviour relating to seeking primary care services". [37]

Thus, future spatial studies require a mixed methods approach where a marrying of the spatial and aspatial dimensions of Penchansky \& Thomas' [12] 'access' needs to occur. This is where geographical access, individual behaviour, individual and public perceptions and the quality of the service are used concurrently to provide a comprehensive understanding of individual and population health seeking behaviours. [6,47,52,58] An individual's perceptions and beliefs are at times, outside the influences of time and distance alone. [59] With some suggesting the perception of access "is more important than absolute measures". [11]
In addition to incorporating greater qualitative data, it must be noted future research also needs to examine other measure of time and distance outside of drivable distance. Within the literature it was noted that car ownership impacted health care accessibility. [47,48] Thus, a future focus may be on those who do not or cannot drive, such as the elderly, new migrants or those who are have low socioeconomic status. [60] A greater focus needs to be undertaken to determine these population's spatial accessibility to health care and if and where health access is attained. [60] This could be achieved by examining walkable distances and public transport routes to identify where health access is not being achieved in metropolitan zones, urban fringes and rural and remote areas. [31]

\section{Conclusion}

Access to primary health care is well recognised as an important facilitator of health and maintaining a population's well-being. Currently the use of GIS in health care is expanding and is used to understand health disparities, aid health care service delivery, planning health care management strategies or meeting health needs of a population. More recently, GIS has also been used to examine and measure health care service accessibility.

Currently there are a plethora of methods used to measure accessibility, many which have evolved to be highlighting specialised methods such as the 2SFCA, 3SFCA and IRA. As health care accessibility becomes more prominent, within policy, among practitioners and increasingly researched, it has the potential to move beyond recognising areas of poor accessibility for individuals and communities. With a greater integration of both spatial and aspatial data, it has the likelihood, to provide greater insight into patient behaviour, public perception and improve service quality.

In addition, it also has the prospect to recognise areas where health care access is poor and support decision making processes. For example, the processes can determine if and where health service gaps exist, what services are lacking, to guide changes in service delivery and where new primary health care services are required to be built, to ensure service access equity. Overall, further research and development will benefit public policy, primary health care service amelioration and ultimately a population's health and wellbeing.

\section{REFERENCES}

[1] Department of Health and Ageing. Towards a National Primary Health Care Strategy: A Discussion Paper from the Australian Government. Canberra: Department of Health and Ageing 2008. 
[2] Kaye B. Clinic developer ignores residents' pleas for a GP. Medical Observer. 20128 October.

[3] World Health Organisation. Declaration of Alma-Ata. 1978 [cited 201221 September]; Available from: http://www.who .int/hpr/NPH/docs/declaration_almaata.pdf.

[4] Ansari Z. A review of literature on access to primary health care. Australian journal of primary health. 2007;13:80-95.

[5] Wong LY, Heng BH, Cheah JTS, Tan CB. Using spatial accessibility to identify polyclinic service gaps and volume of under-served population in Singapore using Geographic Information System. The International Journal of Health Planning and Management. 2012;27:e173-e85.

[6] Bell S, Wilson K, Bissonnette L, Shah T. Access to Primary Health Care: Does Neighborhood of Residence Matter? Annals of the Association of American Geographers. 2013;103:85-105.

[7] McGrail MR. Spatial accessibility of primary health care utilising the two step floating catchment area method: an assessment of recent improvements. International journal of health geographics. 2012;11:50-62.

[8] Wang F. Measurement, Optimization, and Impact of Health Care Accessibility: A Methodological Review. Annals of the Association of American Geographers. 2012;102:1104-12.

[9] Burkey ML. Decomposing geographic accessibility into component parts: Methods and an application to hospitals. Annals of Regional Science. 2012;48:783-800.

[10] Whippo TL. Variable catchment sizes for the two-step floating catchment area method: A case study of accessibility to primary care physicians within two Illinois regions [Masters disertation and theis]. Ann Arbor: Northern Illinois University; 2011.

[11] Schuurman N, Berube M, Crooks VA. Measuring potential spatial access to primary health care physicians using a modified gravity model. The Canadian Geographer. 2010;54 :29-.

[12] Penchansky R, Thomas JW. The concept of access: Definition and relationship to consumer satisfaction. Medical Care 1981;19:127-40.

[13] Khan AA, Bhardwaj SM. Access to Health Care AConceptu al Framework and its Relevance to Health Care Planning. Evaluation \& the health professions. 1994;17:60-7 6.

[14] Eckert KA, Taylor AW, Wilkinson D. Does health service utilisation vary by remoteness? South Australian population data and the Accessibility and Remoteness Index of Australia. Australian and New Zealand Journal of Public Health. 2004;28:426-32

[15] Slifkin RT. Developing Policies Responsive to Barriers to Health Care Among Rural Residents: WhatDo We Need to Know? The Journal of Rural Health. 2002;18:233-41.

[16] Humphreys JS, Wakerman J, Wells R, Kuipers P, Jones JA, Entwistle P. "Beyond workforce": a systemic solution for health service provision in small rural and remote communities. The Medical Journal of Australia. 2008;188:S77-S80.

[17] Maguire DJ. An overview and definition of GIS. In: Maguire
DJ, Goodchild MF, Rhind DW, editors. Geographical information systems: principles and applications. Harlow, Essex, England: Longman Scientific \& Technical; 1991. p. 9-20.

[18] Griffiths E. Geographic Information Systems (GIS) and Spatial Analysis. In: Williams M, Vogt WP, editors. The SAGE Handbook of Innovation in Social Research Methods. London: SAGE; 2011. p. 442-64.

[19] Teach SJ, Guagliardo MF, Crain EF, McCarter RJ, Quint DM, Shao C, et al. Spatial accessibility of primary care pediatric services in an urban environment: association with asthma management and outcome. Pediatrics. 2006;117:S78-S85.

[20] Luo W. Using a GIS-based floating catchment method to assess areas with shortage of physicians. Health \& Place. 2004;10:1-11.

[21] Guagliardo MF, Ronzio CR, Cheung I, Chacko E, Joseph JG. Physician accessibility: an urban case study of pediatric providers. Health \& Place. 2004;10:273-83.

[22] McLafferty SL. GIS and health care. Annual Review of Public Health. 2003;24:25-42.

[23] Bagheri N, Benwell GL, Holt A, editors. Primary Health Care Accessibility for rural Otago: 'A Spatial Analysis'. National Health Informatics Conference 2006; Melbourne: Health Informatics Society of Australia.

[24] Scheffler RM, Liu JX, Kinfu Y, Dal Poz MR. Forecasting the global shortage of physicians: an economic-and needs-based approach. Bulletin of the World Health Organization. 2008;86:516B-23B.

[25] Guagliardo M. Spatial accessibility of primary care: concepts, methods and challenges. International journal of health geographics. 2004;3.

[26] Yang DH, Goerge R, Muliner R. Comparing GIS-based methods of measuring spatial accessibility to health services. J Med Syst. 2006;30:23-32.

[27] Peng Z-R. The jobs-housing balance and urban commuting. Urban studies. 1997;34:1215-35.

[28] Wang F. Modeling commuting patterns in Chicago in a GIS environment: A job accessibility perspective. The Professional Geographer. 2000;52:120-33.

[29] Luo W, Wang F. Measures of spatial accessibility to health care in a GIS environment: synthesis and a case study in the Chicago region. Environment and Planning B: Planning and Design. 2003;30:865-84.

[30] McGrail MR, Humphreys JS. Measuring spatial accessibility to primary care in rural areas: Improving the effectiveness of the two-step floating catchment area method. Applied Geography. 2009;29:533-41.

[31] Roeger LS, Reed RL, Smith BP. Equity of access in the spatial distribution of GPs within an Australian metropolitan city. Australian journal of primary health. 2010;16:284-90.

[32] Radke J, Mu L. Spatial decompositions, modeling and mapping service regions to predict access to social programs. Geographic Information Sciences. 2000;6:105-12.

[33] Wan N, Zou B, Sternberg T. A three-step floating catchment 
area method for analyzing spatial access to health services. International Journal of Geographical Information Science. 2012;26:1073-89.

[34] Wang FH, Luo W. Assessing spatial and nonspatial factors for healthcare access: towards an integrated approach to defining health professional shortage areas. Health \& Place. 2005;11:131-46.

[35] Luo W, Qi Y. An enhanced two-step floating catchment area (E2SFCA) method for measuring spatial accessibility to primary care physicians. Health \& Place. 2009;15:1100-7.

[36] Johnston RJ, editor. The Dictionary of Human Geography. 5th ed. Oxford, United Kingdom: Blackwell Publishers; 2009.

[37] McGrail MR, Humphreys JS. A new index of access to primary care services in rural areas. Australian and New Zealand Journal of Public Health. 2009;33:418-23.

[38] McGrail M, Humphreys J. The index of rural access: an innovative integrated approach for measuring primary care access. BMC Health Services Research. 2009;9:124-36.

[39] Armstrong K, Tess D, Walsh J, Hui Q, Lam W. Technical paper: general practice workforce modelling. Australian Medical Workforce Advisory Committee (AMWAC) \& AMWAC General Practice Working Party, 2005.

[40] Scott J, Larson A, Jefferies F, Veenendaal B. Small-area estimates of general practice workforce shortage in rural and remote Western Australia. Australian Journal of Rural Health. 2006;14:209-13.

[41] Pathman DE, Ricketts rTC, Konrad TR. How adults' access to outpatient physician services relates to the local supply of primary care physicians in the rural southeast. Health services research. 2006;41:79-102.

[42] Bissonnette L, Wilson K, Bell S, Shah TI. Neighbourhoods and potential access to health care: The role of spatial and aspatial factors. Health \& Place. 2012;18:841-53.

[43] Hyndman JCG, Holman CDAJ. Accessibility and spatial distribution of general practice services in an Australian city by levels of social disadvantage. Social Science \& Medicine. 2001;53:1599-609.

[44] Gillespie P, Owens L, Dunne F. Accessibility and screening uptake rates for gestational diabetes mellitus in Ireland. Health and Place. 2012;18:339-48.

[45] McLafferty S, Wang F, Luo L, Butler J. Rural-urban inequalities in late-stage breast cancer: spatial and social dimensions of risk and access. Environment and Planning B-Planning \& Design. 2011;38:726-40.

[46] Brabyn L, Barnett R. Population need and geographical access to general practitioners in rural New Zealand. The New Zealand medical journal. 2004;117:U996-1009.

[47] Comber AJ, Brunsdon C, Radburn R. A spatial analysis of variations in health access: linking geography, socio-economic status and access perceptions. International journal of health geographics. 2011;10:44-55.

[48] Parker EB, Campbell JL. Measuring access to primary medical care: some examples of the use of geographical information systems. Health \& Place. 1998;4:183-93.
[49] Sherman JE, Spencer J, Preisser JS, Gesler WM, Arcury TA. A suite of methods for representing activity space in a healthcare accessibility study. International journal of health geographics. 2005;4:24-46.

[50] Golledge RG, Stimson RJ. Analytical behavioural geography. London: Croom Helm 1987.

[51] Nemet GF, Bailey AJ. Distance and health care utilization among the rural elderly. Social Science \& Medicine. 2000;50:1197-208.

[52] Haynes R, Lovett A, Sunnenberg G. Potential accessibility, travel time, and consumer choice: geographical variations in general medical practice registrations in Eastern England. Environment and Planning A. 2003;35:1733-50.

[53] Astell-Burt T, Flowerdew R, Boyle PJ, Dillon JF. Does geographic access to primary healthcare influence the detection of hepatitis C? Social Science \& Medicine. 2011;72:1472-81.

[54] Monnet E, Ramée C, Minello A, Jooste V, Carel D, Di Martino V. Socioeconomic context, distance to primary care and detection of hepatitis C: A French population-based study. Social Science \& Medicine. 2008;66:1046-56.

[55] Wanga L, Roisman D. Modeling spatial accessibility of immigrants to culturally diverse family physicians. The Professional geographer : the journal of the Association of American Geographers. 2011;63:73-91.

[56] Lê Q, Auckland S, Harris A. A Spatial analysis study of socioeconomics, accessibility and remoteness to primary health care services in Tasmania. Launceston: University of Tasmania, Health UDoR; 2010 October. Report No.

[57] Hawthorne TL, Kwan MP. Using GIS and perceived distance to understand the unequal geographies of healthcare in lower-income urban neighbourhoods. Geographical Journal. 2012;178:18-30.

[58] Arcury TA, Gesler WM, Preisser JS, Sherman J, Spencer J, Perin J. The effects of geography and spatial behavior on health care utilization among the residents of a rural region. Health services research. 2005;40:135-56.

[59] Geurs KT, van Wee B. Accessibility evaluation of land-use and transport strategies: review and research directions. Journal of Transport Geography. 2004;12:127-40.

[60] Jordan H, Roderick P, Martin D, Barnett S. Distance, rurality and the need for care: access to health services in South West England. International journal of health geographics. 2004;3:21-30.

[61] Luo W, Wang F, Douglass C. Temporal changes of access to primary health care in Illinois (1990-2000) and policy implications. J Med Syst. 2004;28:287-99.

[62] Ngui AN, Apparicio P. Optimizing the two-step floating catchment area method for measuring spatial accessibility to medical clinics in Montreal. BMC Health Services Research. 2011;11:166-78.

[63] Peciūra R, Jankauskiene D, Gurevicius R. The search for the criteria in reforming health care: evaluation of the spatial accessibility of primary healthcare service. Medicina (Kaunas). 2006;42:939-43. 